\title{
An Extrarenal Mechanism of Potassium Adaptation
}

\author{
Edward A. Alexander and Norman G. Levinsky with the technical assistance of \\ Patricia BerkLey \\ From the 5th and 6th (Boston University) Medical Services, Boston City Hospital, \\ and the Department of Medicine, Boston University School of Medicine, \\ Boston University Medical Center, Boston, Massachusetts 02118
}

A в S T RACT Rats fed a diet high in potassium for several days survive an acute load of potassium that is lethal to animals on a regular diet. Previous data suggested that this survival occurred because of enhanced kaluresis.

Although increased urinary excretion may occur, the major mechanism of this potassium adaptation phenomenon has been found to be extrarenal. Despite nephrectomy just before study, rats previously fed a high potassium diet maintained lower plasma potassium concentrations for at least $2 \mathrm{hr}$ after an acute potassium load than did rats fed a regular diet.

Prior adrenalectomy abolished adaptation. Furthermore, rats fed a low sodium diet as an alternative stimulus to aldosterone secretion demonstrated adaptation to potassium loading, as did adrenalecomized rats given large doses of deoxycorticosterone for several days. Adrenalectomy just before the test load of potassium did not abolish adaptation nor did a large dose of aldosterone at that time reproduce it. These data indicate that adaptation is dependent on a chronic increase in aldosterone secretion.

The extra potassium removed from the extracellular fluid by adapted rats was not lost into

This study was presented in part before the 58th Annual Meeting of the American Society for Clinical Investigation, 1 May 1966. An abstract of this study has been published in 1966, J. Clin. Invest. 45: 980.

Dr. Levinsky is an Established Investigator of the American Heart Association.

Address requests for reprints to Dr. Norman G. Levinsky, Boston University School of Medicine, 15 Stoughton Street, Boston, Mass. 02118.

Received for publication 29 March 1967 and in revised form 14 July 1967. the gastrointestinal tract. It is concluded that more rapid lowering of plasma potassium after acute potassium loads by adapted rats is due to enhanced uptake of potassium by one or more tissues stimulated by chronic aldosteronism.

\section{INTRODUCTION}

Animals given a large load of potassium are protected against lethal hyperkalemia by two mechanisms. First, most of the administered potassium rapidly enters tissues $(1,2)$. Second, renal excretion of potassium quickly increases, and a large fraction of the potassium load is excreted within a few hours (3). In 1947 Thatcher and Radike (4) reported that rats previously maintained on a large potassium intake survive an acute dose of potassium that is lethal to rats on a normal diet. A few years later, Berliner, Kennedy, and Hilton (3) confirmed this phenomenon in dogs and also noted that the rate of urinary potassium excretion during intravenous infusion of potassium was more rapid in dogs previously on a high potassium diet than in dogs on a regular diet. Berliner and associates were unable to determine the mechanism of the increased excretory capacity for potassium but suggested that it was not due to increased mineralocorticoid activity.

Although no equivalent observations have been made in rats, it has generally been assumed that potassium tolerance in the rat as in the dog is related to increased renal excretory capacity. In the present studies there is suggestive evidence that the rat, like the dog, may develop increased excretory capacity in response to chronic potassium loading. However, it appears from our data that 
the mechanism which enables potassium-fed rats to survive acute loading is extrarenal, and that this extrarenal mechanism is aldosterone dependent.

\section{METHODS}

Male Sprague-Dawley or Charles River rats weighing 125-175 g were used in all experiments. They were maintained on one of the following three diets: (a) regular, Purina lab chow, potassium content $0.72 \%$; $(b)$ high potassium, powdered lab chow containing $10 \%$ potassium chloride; or $(c)$ low sodium, ${ }^{1}$ potassium content $0.92 \%$. Experiments were performed after the rats had been on the appropriate diet for 4-6 days. During this period of feeding, rats on the regular diet gained approximately 35-50 $\mathrm{g}$ whereas those on the high potassium diet gained $10-20 \mathrm{~g}$, and those on the low sodium diet gained about 25-35 g.

Food was removed $16-20 \mathrm{hr}$ before study. At the start of an experiment the animals were lightly anesthetized with ether. When urine was to be collected, a ligature was placed around the penis after the bladder had been emptied by pressure. An acute loading dose of $0.3 \mathrm{M}$ potassium chloride, $5 \mathrm{mmoles} / \mathrm{kg}$, was injected intraperitoneally immediately after the penis had been ligated. The rats were then allowed to recover from anesthesia. 1 or $2 \mathrm{hr}$ after the loading dose, the rats were again anesthetized. Blood was collected via a heparinized syringe from the abdominal aorta. Care was taken to avoid hemolysis; obviously hemolyzed samples were discarded. The bladder was clamped at its base, removed, emptied, and then washed several times with distilled water; the washes were added to the urine. In other experiments, the rats were nephrectomized immediately before the acute potassium load. These rats were given $2.5 \mathrm{mmoles} / \mathrm{kg}$ of $0.3 \mathrm{M}$ potassium chloride intraperitoneally as the loading dose. Virtually all rats, both intact and nephrectomized, survived to the end of the acute loading experiment.

In most studies in which adrenalectomized rats were used, they were given $0.82 \%$ saline to drink ad lib. 4-8 days after surgery they were started on the appropriate diet, and daily subcutaneous injections of $0.2 \mathrm{mg}$ of deoxycorticosterone acetate in oil (DOCA) were begun. In other experiments in which adrenalectomized rats ate a low sodium diet and drank tap water ad lib., they received $0.75 \mathrm{mg}$ of DOCA or more daily.

Tissue electrolytes were measured in the following manner. Muscle fibers were dissected as free of tendon and fat as possible, blotted once on filter paper, finely minced, placed in tared test tubes, and weighed. They were then dried under vacuum at room temperature for 19-21 $\mathrm{hr}$ and reweighed to obtain dry weights. Electrolytes were extracted in boiling water for $1 \mathrm{hr}$. Pieces of liver, lung, and whole spleen were treated in a similar manner. The entire gastrointestinal tract, from the esophogeal-cardiac junction to the recto-sigmoid junction, and its contents were removed, weighed, and minced in

\footnotetext{
1 Nutritional Biochemicals Corporation, Cleveland, Ohio; low sodium test diet.
}

a blender containing $50 \mathrm{ml}$ of distilled water. An aliquot of this material was then boiled for $1 \mathrm{hr}$ to extract electrolytes. Erythrocyte potassium was measured on an aliquot of dried erythrocytes that had been separated from whole blood by centrifugation, weighed, diluted with distilled water, and boiled for $1 \mathrm{hr}$. Correction for plasma trapping was not made. In a few studies, intracellular potassium concentration was estimated from chloride space determinations. Analytical methods were as follows: sodium and potassium, flame photometry; chloride, Cotlove chloridimeter ; magnesium, flame absorption spectrometry ; carbon dioxide content of arterial blood drawn under oil, Van Slyke manometry. Standard statistical techniques were used. Values are reported as means \pm standard deviation. Each plasma potassium value given in the text or figures is a mean from at least 10 animals.

When certain experiments were repeated in the course of these studies, it was found that the differences between control and test groups of rats were reproducible. However, the absolute levels of plasma potassium for groups of rats treated identically varied considerably from experiment to experiment. Hence, in virtually all cases, data are derived from comparison of control and test rats that were prepared and studied simultaneously. A single exception is noted in the legend to Fig. 6.

\section{RESULTS}

Effect of an acute potassium load on plasma $K$ and urinary excretion. The rats had been fed either a regular or high potassium diet. In Fig. 1 it may be seen that rats fed these diets had comparable plasma potassium levels : $4.2 \mathrm{mEq} /$ liter in the rats on the high potassium diet, $4.4 \mathrm{mEq} /$ liter in the rats on the regular diet. Thus, there was no evidence that a diet very high in potassium alters fasting plasma potassium levels. Groups of animals were challenged with $5 \mathrm{mmoles} / \mathrm{kg}$ of potassium chloride intraperitoneally. Separate studies indicated that over $90 \%$ of this dose is absorbed

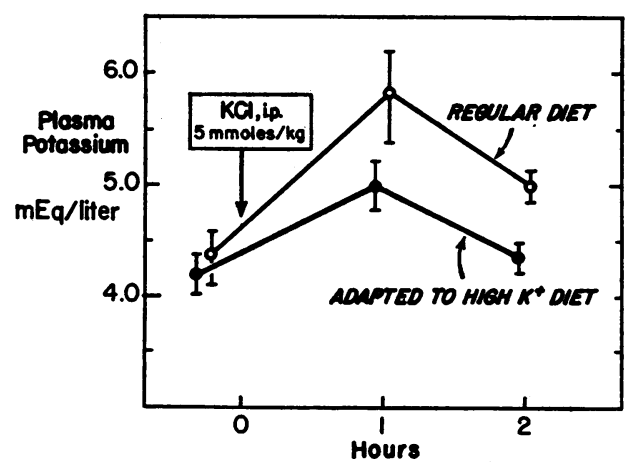

Figure 1 Effect of an acute potassium load on plasma potassium in rats fed a regular or a high $\mathrm{K}$ diet. Points are means; vertical lines show $\pm \mathrm{SE}$ in this and all subsequent figures. 


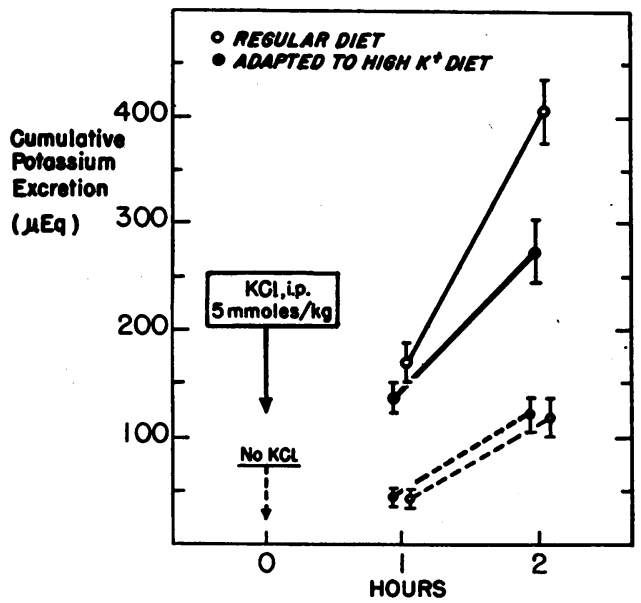

Figure 2 Cumulative urinary potassium excretion. The solid lines in the upper section show excretion after an acute $\mathrm{KCl}$ load. The broken lines in the lower section show the basal excretion when an acute load was not given. All rats were fasting for $16-20 \mathrm{hr}$ before each study.

within $2 \mathrm{hr}$, as had previously been shown by others (1). The rats fed the high potassium diet had a lower plasma potassium concentration both at $1 \mathrm{hr}(5.0 \pm 0.9$ vs. $5.8 \pm 1.4 \mathrm{mEq} /$ liter $)$ and at $2 \mathrm{hr}(4.3 \pm 0.5$ vs. $5.0 \pm 0.5 \mathrm{mEq} /$ liter after the acute potassium load. The differences were significant at both times $(P<0.01)$.

If renal excretory adaptation accounted for the lower plasma potassium in the rats on the high potassium diet, excretion should be greater in those rats than in the rats fed the regular diet. On the contrary, the reverse was the case. In Fig. 2, the solid lines in the upper section indicate that potassium excretion was equal in both groups at $1 \mathrm{hr}$ after the same acute load; at $2 \mathrm{hr}$, excretion was actually less in the rats fed extra potassium than in the controls $(274 \pm 138 \mu \mathrm{Eq}$ vs. $404 \pm 131 \mu \mathrm{Eq}, P<0.01)$. As shown by the broken lines at the bottom of the graph, basal urinary potassium excretion when the acute load was not given was relatively low and equal in the two groups. The low basal excretory rate is due to the fact that the rats had been fasting $16-20 \mathrm{hr}$ before study. Thus, the difference in excretion after intraperitoneal potassium reflects a different response to the acute load rather than variations in basal excretion on the different diets.

Effect of nephrectomy on adaptation. For convenience, rats that maintain lower plasma potas- sium concentrations after acute loading than do control rats will be described as "adapted" and this phenomenon as "adaptation." The data in the preceding section suggest that adaptation is due to a nonrenal mechanism. To confirm this, rats fed regular or high potassium diets where nephrectomized a few minutes before receiving 2.5 mmoles $/ \mathrm{kg} \mathrm{KCl}$ intraperitoneally. This reduced load was used because preliminary experiments demonstrated that nephrectomized rats on both diets either died or were very hyperkalemic (plasma potassium over $8 \mathrm{mEq} /$ liter) if given the larger dose used in rats with intact kidneys. At $1 \mathrm{hr}$ after the acute load rats fed the high potassium diet had a plasma $\mathrm{K}$ of $4.4 \pm 0.7 \mathrm{mEq} /$ liter and at $2 \mathrm{hr} 5.4 \pm 0.8 \mathrm{mEq} /$ liter, whereas the rats fed a regular diet had a plasma $\mathrm{K}$ of $5.6 \pm 0.8$ and $7.4 \pm 2.1 \mathrm{mEq} /$ liter at the same times. These results are illustrated in Fig. 3. In a repetition of this experiment some months later plasma potassium levels were $4.9 \pm 0.4$ and $5.7 \pm 0.6 \mathrm{mEq} /$ liter at $2 \mathrm{hr}$ in adapted and regular rats respectively $(P<0.001)$. These experiments demonstrate definitively that a nonrenal mechanism accounts for the enhanced ability of rats fed a high potassium diet to clear potassium from the plasma.

Relation of adrenal glands to potassium adaptation. Since a high potassium diet is known to stimulate aldosterone secretion, the influence of the adrenal gland on this nonrenal mechanism was investigated. An experiment was performed with adrenalectomized rats maintained on a daily dose

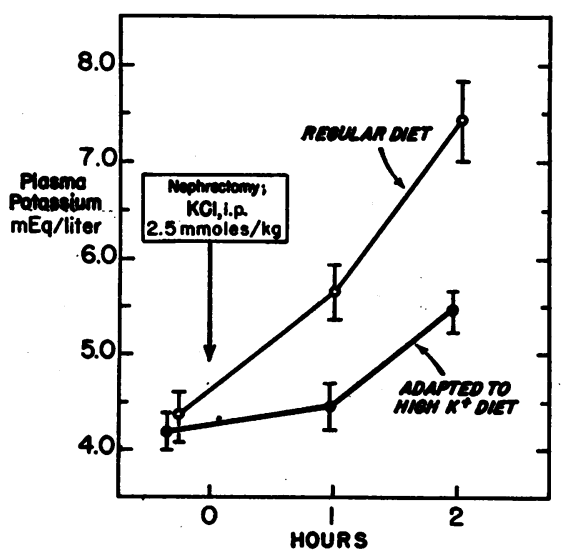

Figure 3 Response of nephrectomized rats to an acute potassium load. 


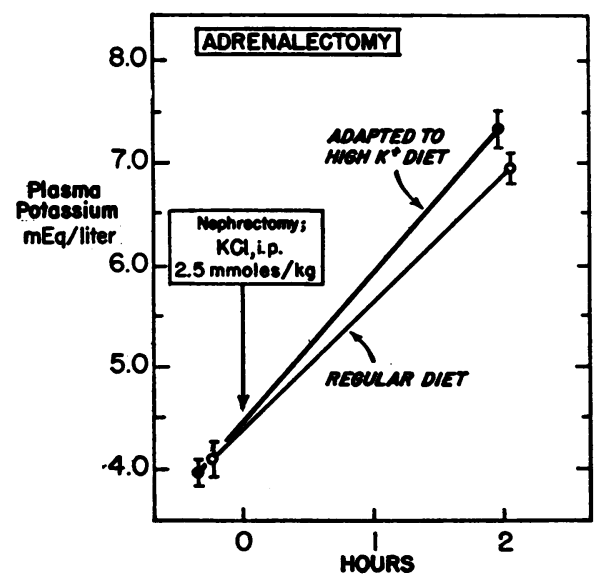

FIGURE 4 Effect of adrenalectomy on the response of nephrectomized rats to an acute potassium load. The rats had been adrenalectomized 2 wk before study and were maintained on $0.15-0.20 \mathrm{mg}$ of deoxycorticosterone acetate (DOCA) daily.

of $0.15-0.20 \mathrm{mg}$ of DOCA in oil during the 5-6 days when they ate either the regular or the high potassium diet. The results are illustrated in Fig. 4. Note that the plasma potassium levels before acute loading were similar in both groups. After the acute dose of potassium chloride, plasma potassium was similar in both groups, reaching values of $6.9 \pm 0.7$ and $7.3 \pm 0.6 \mathrm{mEq} /$ liter $(P>0.1)$. These data show that adrenalectomy eliminates adaptation.

It was noted that the adrenal weights of rats fed thes high potassium diet were significantly greater than those of control rats, $26.6 \pm 5 \mathrm{mg}$ vs. $22.0 \pm 3 \mathrm{mg}(P<0.01)$. It was not possible to measure aldosterone levels in these experiments. However, plasma levels of corticosterone, ${ }^{2}$ the principal glucocorticoid in the rat, were similar in the high $\mathrm{K}$ and regularly fed rats (high potassium diet, $28.0 \pm 10 \mu \mathrm{g} / 100 \mathrm{ml}$; regular diet, 35.7 $\pm 14 \mu \mathrm{g} / 100 \mathrm{ml}, P>0.2$ ). These data suggest that the adrenal hypertrophy is related to the secretion of a steroid other than corticosterone.

From the results of these experiments, it seemed reasonable that increased aldosterone activity was required for the operation of the adaptive mechanism. Since aldosterone secretion is stimulated by a low sodium diet as well as by a high potassium diet, rats were tested to see if adaptation to acute potassium loads would develop on a low sodium,

${ }^{2} \mathrm{We}$ are indebted to Dr. James Melby, Boston University Medical Center, for the corticosterone analyses. normal potassium diet. Fig. 5 demonstrates that this is in fact the case. At $2 \mathrm{hr}$ after nephrectomy and potassium loading, mean plasma $\mathrm{K}$ in the rats on the low sodium diet was $5.2 \pm 0.5 \mathrm{mEq} / \mathrm{liter}$, whereas plasma potassium in rats on a regular diet was $6.1 \pm 0.5 \mathrm{mEq} /$ liter, $0.9 \mathrm{mEq} /$ liter higher. To eliminate the possibility that the low sodium diet induced adaptation by some nonadrenal mechanism, adrenalectomized rats maintained on a low sodium diet and $0.75 \mathrm{mg}$ of DOCA daily were tested for adaptation. The results are shown by the solid circles in Fig. 6 . The mean control plasma potassium was $4.4 \pm 0.5 \mathrm{mEq} /$ liter. $2 \mathrm{hr}$ after nephrectomy and an acute potassium load, the plasma potassium was $7.4 \pm 1.2 \mathrm{mEq} /$ liter, a value clearly different from the adapted animals on a low sodium diet (open circles in Fig. 6) and virtually the same as the adrenalectomized animals on high $\mathrm{K}$ diet in previous experiments (solid circles, Fig. 4).

These experiments strongly suggest that adaptation is induced by increased aldosterone secretion. Two types of aldosterone secretion might be involved. Adaptation might be induced by the chronic increase in secretion during the 5 days on the high potassium diet. Alternatively, adaptation might be due to acute hypersecretion of aldosterone by a chronically hyperfunctioning adrenal in response to the acute potassium load (5). To determine whether the acute effect of very large amounts of mineralocorticoids could induce adaptation, two studies were performed. In the first, control rats and rats on a high potassium diet were adrenalectomized and nephrectomized just before an acute load of potassium, 2.5 mmoles $/ \mathrm{kg}$. Plasma potassium $2 \mathrm{hr}$ after the test dose was $5.8 \pm 0.3 \mathrm{mEq} /$ liter in the rats on the

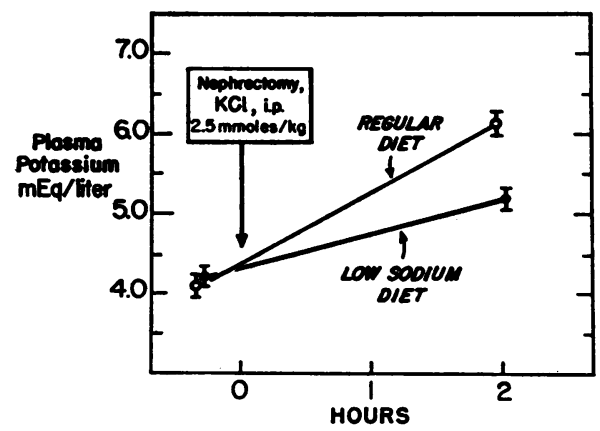

Figure 5 Effect of a low sodium diet on the response to an acute potassium load. 


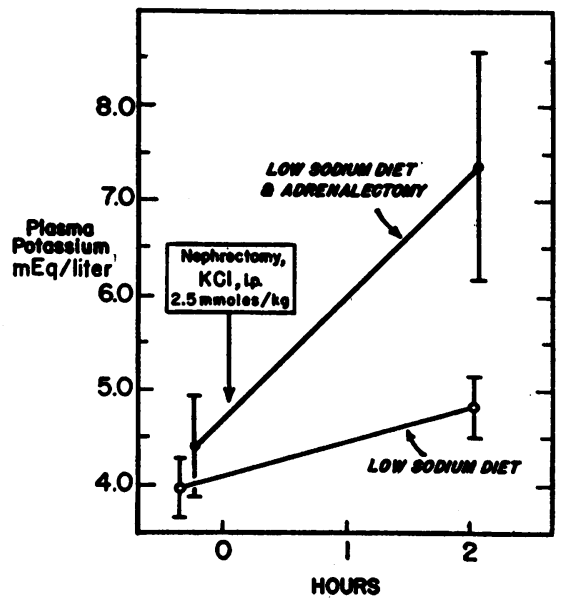

Figure 6 Effect of a low sodium diet on response to an acute potassium load in intact and adrenalectomized rats. The intact and adrenalectomized animals were not litter mates and were not studied simultaneously.

high potassium diet and $6.4 \pm 0.9 \mathrm{mEq} /$ liter in the rats on the regular diet $(P<0.05)$. Thus, adaptation occurred despite the removal of the adrenals immediately before testing. In another experiment, rats fed the regular diet were given $20 \mu \mathrm{g}$ of aldosterone intraperitoneally just before nephrectomy and the acute potassium load. $2 \mathrm{hr}$ later plasma potassium was $5.8 \pm 0.7 \mathrm{mEq} /$ liter in these rats, compared to $4.6 \pm 0.8 \mathrm{mEq} /$ liter in rats adapted on a high $\mathrm{K}$ diet $(P<0.01)$. Thus, there is no evidence that a single large dose of aldosterone can acutely recreate the adaptation phenomenon.

The following experiment was done as a direct test of the alternative possibility that adaptation is the result of a chronic increase in mineralocorticoid secretion. Adrenalectomized rats maintained on a low sodium diet and tap water were divided into four groups that were injected, respectively, with $0.75,1.25,5$, or $7.5 \mathrm{mg}$ of DOCA in oil daily. The diet and injections were continued for 4 days. The diet was not withdrawn on the night before the experiment, as was done in all the preceding studies. On the 5 th day, the rats were nephrectomized and tested for adaptation by the intraperitoneal injection of $2.5 \mathrm{mmoles} /$ $\mathrm{kg}$ potassium chloride. The data from the first two groups were entirely comparable, as were those from the last two groups. Hence, the results were pooled into two groups, low DOCA and high DOCA, as shown in Fig. 7. $2 \mathrm{hr}$ after the acute potassium load, plasma potassium was $7.6 \pm 0.7$ $\mathrm{mEq} /$ liter in the low DOCA group and $6.2 \pm 0.6$ $\mathrm{mEq} /$ liter in high DOCA group. The difference was highly significant $(P<0.01)$. Plasma potassium was normal and identical in control rats from both groups which were not acutely loaded with potassium, as shown in Fig. 7 (high DOCA, $4.4 \pm 0.4 \mathrm{mEq} /$ liter; low DOCA, $4.4 \pm$ $0.8 \mathrm{mEq} /$ liter ). To further document that the low sodium diet had prevented potassium depletion in the high DOCA group, muscles from each control group were analyzed for potassium. Muscle potassium was $41.5 \pm 2.5 \mathrm{mEq} / 100 \mathrm{~g}$ dry weight in the low DOCA, and $41.3 \pm 2 \mathrm{mEq} / 100 \mathrm{~g}$ dry weight in the high DOCA, control group. This experiment is strong direct evidence for the view that adaptation is due to a chronic increase in mineralocorticoid secretion.

Tissue analysis. The results described above demonstrate that in adapted rats there is accelerated removal of potassium from the plasma by a nonrenal route. An alternative pathway for loss is the gastrointestinal tract. To determine whether potassium enters the gut more rapidly in adapted than in control rats, the potassium content of the gastrointestinal tract and contained feces was measured before and after acute potassium loading. The results are presented in the first line of Table I. The potassium content of the gut was equal in control and adapted rats before the acute load of potassium. (Both groups were fasted for 16-20

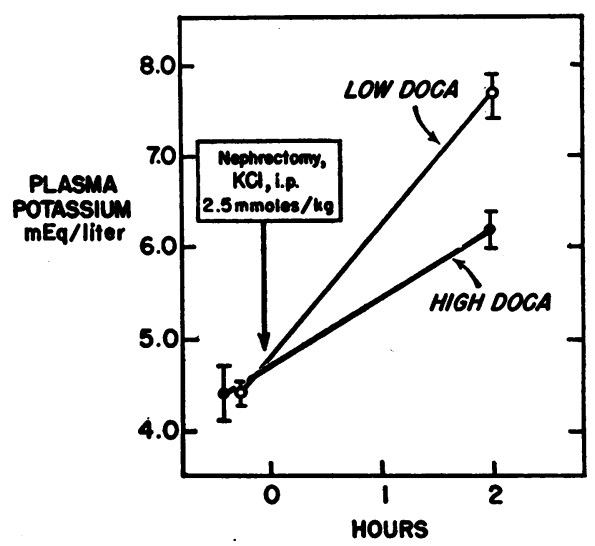

Figure 7 Effect of high (5-7.5 mg/day) and low (0.75-1.25 mg/day) doses of DOCA on the response of nephrectomized rats to an acute potassium load. The rats had been on DOCA for 4 days before the experiment. All rats were on a low sodium diet to prevent potassium depletion. 
TABLE I

Tissue Analyses in Rats Fed High Potassium Diet

\begin{tabular}{|c|c|c|c|c|c|}
\hline & \multirow[b]{2}{*}{ Weight* } & \multicolumn{2}{|c|}{ Before $\mathrm{K}$ loading } & \multicolumn{2}{|c|}{ After $\mathrm{K}$ loading } \\
\hline & & Regular & High $\mathrm{K}$ & Regular & High $\mathrm{K}$ \\
\hline & & \multicolumn{4}{|c|}{$m E q / 100 \mathrm{~g} d r y w t$} \\
\hline Gastrointestinal tract + & 12.0 & $64 \pm 3(21) \ddagger$ & $62 \pm 2(21)$ & $64 \pm 2(21)$ & $62 \pm 7(22)$ \\
\hline Diaphragm & 0.075 & $40 \pm 3(42)$ & $37 \pm 4(41)$ & $41 \pm 3(40)$ & $40 \pm 4(41)$ \\
\hline Gastrocnemius & & $47 \pm 3(23)$ & $45 \pm 3(22)$ & $48 \pm 4(23)$ & $47 \pm 3(23)$ \\
\hline Liver & 1.5 & $23 \pm 3(18)$ & $24 \pm 3(18)$ & $23 \pm 3(18)$ & $26 \pm 3(18)$ \\
\hline Spleen & 0.125 & $48 \pm 2(7)$ & $45 \pm 5(6)$ & $46 \pm 1(7)$ & $48 \pm 2(8)$ \\
\hline Lung & 0.250 & $33+3(17)$ & $31 \pm 3(13)$ & $30 \pm 2(17)$ & $30 \pm 4(19)$ \\
\hline Erythrocytes & & $26 \pm 2(5)$ & $24 \pm 2(5)$ & $25 \pm 2(6)$ & $25 \pm 2(5)$ \\
\hline
\end{tabular}

* Mean dry weight of whole organs of all groups of rats. Values for gastrointestinal tract are wet weight of whole organ and contents.

$\ddagger$ Mean \pm SD. Number of rats in parenthesis. Values for gastrointestinal tract are milliequivalents per whole organ wet weight.

$\mathrm{hr}$ before tissue analysis.) $2 \mathrm{hr}$ after acute intraperitoneal potassium loading, gastrointestinal potassium had not increased significantly in either group of rats. Thus, lower plasma potassium in adapted rats is not achieved by excretion of additional potassium into the gut.

Since observation indicated that no vomiting occurred after acute potassium loading, and no extra potassium was lost into urine or gut, lower plasma potassium in adapted rats must be due to increased movement of potassium into tissues. The potassium content of various tissues before and after acute potassium loading was measured in groups of rats fed regular or high potassium diets. The results are given in Table I. Before potassium loading, there was a general tendency toward lower potassium content in all organs studied except the liver in the rats fed the high potassium diet. However, this tendency was not statistically significant in any case. except for diaphragm muscle. After acute loading, there was an increase in potassium content in some organs in both groups of rats; this increase did not occur in lung or, as previously noted, in the gut. However, this tendency toward increased potassium content was statistically significant only in the diaphragm in the rats on the high potassium diet. When control and adapted rats were compared, the increment in potassium content after the acute load was not statistically different in any organ except diaphragm and spleen. More potassium entered these organs after loading in adapted than in control rats.
The potassium content of various tissues was also determined in rats on the low sodium diet and in a control group studied simultaneously. The results are shown in Table II. There was no difference in potassium content between the two groups in any of several muscles studied. Potassium content in spleen and lung was slightly greater in the rats fed the low sodium diet; the latter difference was statistically significant $(P$ $<0.01)$. Additional rats from each group were nephrectomized and tested for adaptation. $2 \mathrm{hr}$ after potassium loading, plasma $\mathrm{K}$ was $6.3 \pm 0.6$ $\mathrm{mEq} /$ liter in the control rats and $5.4 \pm 0.6 \mathrm{mEq} /$ liter in the rats on the low sodium diet $(P<$ $0.001)$. These data are in good agreement with those obtained in the comparable earlier experiment shown in Fig. 5 and demonstrate that the rats on the low sodium diet whose tissues were analyzed were in fact adapted.

TABLE II

Tissue Analyses in Rats Fed Low Sodium Diet

\begin{tabular}{|c|c|c|}
\hline & \multicolumn{2}{|c|}{ Before $\mathrm{K}$ loading } \\
\hline & Regular & Low Na diet \\
\hline & \multicolumn{2}{|c|}{$m E q / 100 \mathrm{~g} d r y w t$} \\
\hline Diaphragm & $39 \pm 1(16)^{*}$ & $40 \pm 1(14)$ \\
\hline Gastrocnemius & $46 \pm 2(13)$ & $46 \pm 2(29)$ \\
\hline Paravertebral muscles & $47 \pm 2(16)$ & $46 \pm 3(14)$ \\
\hline Triceps & $45 \pm 3(16)$ & $45 \pm 3(14)$ \\
\hline Heart & $33 \pm 1(16)$ & $33 \pm 1(14)$ \\
\hline Spleen & $44 \pm 5(14)$ & $46 \pm 5(15)$ \\
\hline Lung & $27 \pm 3(14)$ & $30 \pm 2(15)$ \\
\hline
\end{tabular}

* Mean \pm SD. Number of rats in parenthesis. 
Isolated diaphragm. To test the possibility that adaptation reflects the ability of skeletal muscles to maintain an increased concentration gradient for potassium, in vitro studies were performed. Isolated rat diaphragms were maintained in Ringer's medium for 3 or $5 \mathrm{hr}$ at a fixed external potassium, by the technique of Relman, Gorham, and Levinsky (6). In each experiment, diaphragms from potassium-fed and control rats were maintained in the same box of medium. Separate experiments were done at external potassium concentrations of 0.6 and $6.0 \mathrm{mEq} /$ liter. At $0.6 \mathrm{mEq} /$ liter, muscle from both adapted and control rats maintained a potassium content of $21 \mathrm{mEq} / 100 \mathrm{~g}$ dry weight. At $6 \mathrm{mEq} /$ liter of potassium in the medium, muscle from adapted rats contained 34 $\mathrm{mEq} / 100 \mathrm{~g}$ of dry weight and muscle from control rats $36 \mathrm{mEq} / 100 \mathrm{~g}$ dry weight. Thus, there were no significant differences in in vitro equilibrium potassium content at either external potassium level.

Plasma electrolytes. Plasma sodium concentrations were equal in control and adapted rats (adapted, $142 \mathrm{mEq} /$ liter ; control, $143 \mathrm{mEq} /$ liter). Plasma carbon dioxide was not different: 23.5 mmoles/liter in adapted rats and 21.7 mmoles/liter in control rats. After acute potassium loading, the mean plasma carbon dioxide content was reduced 3 mmoles/liter in the adapted group and 2.5 mmoles/liter in the control group. Plasma magnesium levels were found to be slightly, but significantly, lower in the adapted rats, $1.45 \pm 0.15$ $\mathrm{mEq} /$ liter, than in the control rats., $1.63 \pm 0.17$ $\mathrm{mEq} /$ liter $(P<0.001)$. In adrenalectomized rats maintained on $0.75 \mathrm{mg}$ of DOCA daily, there was no difference in plasma magnesium between the rats on the regular $(1.34 \mathrm{mEq} /$ liter $)$ and on the high potassium diet $(1.31 \mathrm{mEq} /$ liter $)$.

\section{DISCUSSION}

The phenomenon of potassium tolerance was first described in detail by Thatcher and Radike (4). They maintained rats on progressively increasing daily doses of potassium and showed that after 10 days these animals survived an acute load of potassium chloride which killed $100 \%$ of rats that had not been given prior potassium supplements. Berliner, Kennedy, and Hilton (3) found that dogs on a high potassium intake $(10 \mathrm{~g} /$ day $)$ responded to intravenous potassium loads quite differently than dogs on a normal diet. Urinary potassium excretion radidly rose virtually to the rate of infusion in the potassium-fed dogs, whereas plasma potassium did not become greatly elevated. Dogs on a normal diet excreted potassium less rapidly in response to intravenous infusion, and their plasma potassium increased markedly. Potassium tolerance has since been considered an adaptive property of the kidney although the mechanism has been unexplained. Berliner and associates gave DOCA both in acute and chronic studies to see whether increased mineralocorticoids would duplicate the phenomenon. Results were inconclusive because all the dogs became potassiumdepleted on DOCA.

There is some evidence for enhanced renal excretory capacity in the present studies. In Fig. 2 it may be seen that at $1 \mathrm{hr}$ the potassium-adapted rats, although they had a plasma potassium of $0.8 \mathrm{mEq} /$ liter lower than the controls, had excreted the same amount of potassium in the urine. The ability of the adapted rats to excrete potassium as rapidly as control rats despite a lower plasma concentration may be analogous to the observations of Berliner and associates in dogs (3). The adapted rats excreted less potassium than the controls in the $2 \mathrm{nd} \mathrm{hr}$ after the acute load. This discrepancy is probably due to the fact that in the adapted rats plasma potassium had already been lowered to normal by the extrarenal mechanism, thereby removing the acute stimulus to accelerated renal excretion.

Although plasma potassium levels were comparable, the potassium content of most tissues tended to be slightly lower in rats adapted on a high potassium diet than in controls. ${ }^{3}$ We cannot rule out the possibility that minimal potassium depletion was a factor in adaptation induced by the high potassium diet. However, the differences

${ }^{3}$ Although the possibility that potassium depletion might be produced by a high potassium diet seems paradoxical, there are a few data in the literature which might fit with this possibility. In 1940, Miller and Darrow (14) maintained a group of rats on a $2 \%$ potassium chloride diet for 24-51 days and found that although plasma potassium levels were normal, muscle potassium was somewhat reduced. Drescher, Talbot, Meara, Terry, and Crawford (15) noted that the potassium content of heart was at or below the lower limit of normal in rats fed a diet very high in potassium. Plasma potassium concentration was elevated in these rats. 
in tissue potassium were not statistically significant, except for diaphragm. Moreover, tissue potassium was not reduced at all in rats adapted on the low sodium diet (Table II; experiment in Fig. 7). Hence, prior minimal potassium depletion cannot explain adaptation in these experiments.

It seems quite clear from the evidence presented in this paper that a potent nonrenal mechanism accounts for adaptation. The evidence that the adrenal gland, and specifically aldosterone, is necessary for adaptation is also quite strong and may be summarized as follows. High potassium intake is a known stimulus to aldosterone secretion (7). The rats fed the high potassium diet had larger adrenal glands than rats on a regular diet; plasma levels of corticosterone, the major glucocorticoid of the rat, were not different in the two groups. Furthermore, increased aldosterone secretion is known to cause hypomagnesemia (8) which occurred in adapted rats with intact adrenals but not in adrenalectomized rats on the same high potassium diet. Adrenalectomized rats maintained on a fixed amount of DOCA did not become adapted on a high potassium diet (Fig. 4). Adaptation could be reproduced by another stimulus to aldosterone secretion (7): a low sodium diet (Fig. $5)$. Finally, adaptation could be reproduced by chronic administration of large amounts of DOCA (Fig. 7). These data are strong evidence for the thesis that adaptation is mediated by stimulation of aldosterone secretion rather than by any other effect of the high potassium diet.

Cannon, Ames, and Laragh (5) have recently suggested that the effect of a potassium load on aldosterone secretion is directly related to the preexisting level of adrenal function. Since the adrenals of adapted rats are under prolonged dietary stimulation, it seemed possible that adaptation was an effect of a huge burst of aldosterone secreted in response to the acute potassium load. However, acute adrenalectomy just before potassium loading does not eliminate adaptation. Moreover, adaptation was not reproduced by large acute doses of aldosterone given to control rats. Thus, it would appear that adaptation is due not to acute hypersecretion of aldosterone but to the effects of chronic aldosteronism.

How might aldosterone alter the nonrenal handling of potassium? One possibility might be that aldosterone enhances loss of potassium via the gut, since it has been shown that aldosterone increases potassium secretion into the gastrointestinal tract of the dog (9). However, our data demonstrate that gastrointestinal excretion is not increased after acute potassium loading in adapted rats (Table I). It is well known that when a large dose of potassium is given, most of it rapidly leaves the extracellular space and enters tissues $(1,2)$. Since potassium is not lost externally in adapted rats, adaptation must represent an acceleration of this process in one or more tissues in response to chronic aldosteronism. However, tissue analysis did not show any difference between regular and adapted rats in potassium uptake after acute loading. The analytical methods used for tissue analysis were sufficiently sensitive to detect the expected increment in potassium easily had it entered any of the tissues studied except muscle. Therefore, it is possible that adaptation is due to accelerated uptake of potassium by muscle despite our inability to demonstrate this hypothesis by tissue analysis. No evidence for such an effect was obtained from our in vitro experiments when the isolated rat diaphragm was used. An alternative explanation is that accelerated uptake may occur in many different tissues, so that the amount added to any single tissue is too small to be identified by our analytical techniques. This explanation would imply a generalized tissue effect of aldosterone. A number of previous studies have suggested that aldosterone does have a direct effect on the electrolyte content of muscle or other tissues (10-13). In our opinion, most of the data have been difficult to interpret and have not been wholly convincing. However, our data are consonant with the thesis that chronic aldosteronism may accelerate potassium uptake into one or more tissues when plasma potassium concentration is acutely elevated.

\section{ACKNOWLEDGMENTS}

This study was supported in part by U. S. Public Health Service Research Grants HE-06795, HE-09584, and AM05589.

Dr. Alexander is a postdoctoral fellow (5-F2-HE-24, 806-02) of the National Heart Institute.

\section{REFERENCES}

1. Noonan, T. R., W. O. Fenn, and L. Haege. 1941. The distribution of injected radioactive potassium in rats. Am. J. Physiol. 132: 474.

2. Bourdillon, J. 1937. Distribution in body fluids and excretion of ingested ammonium chloride, potassium 
chloride, and sodium chloride. Am. J. Physiol. 120: 411.

3. Berliner, R. W., T. J. Kennedy, Jr., and J. G. Hilton. 1950. Renal mechanisms for excretion of potassium. Am. J. Physiol. 162: 348.

4. Thatcher, J. S., and A. W. Radike. 1947. Tolerance to potassium intoxication in the albino rat. $A m$. J. Physiol. 151: 138.

5. Cannon, P. J., R. P. Ames, and J. H. Laragh. 1966. Relation between potassium balance and aldosterone secretion in normal subjects and in patients with hypertensive or renal tubular disease. J. Clin. Invest. 45: 865.

6. Relman, A. S., G. W. Gorham, and N. G. Levinsky. 1961. The relation between external potassium concentration and the electrolyte content of isolated rat muscle in the steady state. J. Clin. Invest. 40: 386.

7. Davis, J. O., J. Urquhart, and J. T. Higgins, Jr. 1963. The effects of alterations of plasma sodium and potassium concentration on aldosterone secretion. $J$. Clin. Invest. 42: 597.

8. Hanna, S., and I. MacIntyre. 1960. The influence of aldosterone on magnesium metabolism. Lancet. 2 : 348.

9. Shields, R., and R. G. Elmslie. 1962. The effect of aldosterone on absorption of water and electrolytes from the ileum and colon of the dog. Brit. J. Surg. 50: 96. (Abstr.)

10. Ingle, D. J., H. W. Nilson, and E. C. Kendall. 1937. The effect of cortin on the concentrations of some constituents of the blood of adrenalectomized rats. Am. J. Physiol. 118: 302.

11. Santos, R. F. 1959. Extrarenal action of adrenal glands on potassium metabolism. Am. J. Physiol. 197: 643.

12. Woodbury, D. M., and A. Koch. 1957. Effects of aldosterone and deoxycorticosterone on tissue electrolytes. Proc. Soc. Exptl. Biol. Med. 94: 720.

13. Tompkins, M. J., E Eckman, and L. Share. 1959. Extrarenal action of the adrenal cortex on electrolyte metabolism in nephrectomized and nephrectomizedeviscerated rats. Am. J. Physiol. 196: 141.

14. Miller, H. C., and D. C. Darrow. 1940. Relation of muscle electrolyte to alterations in serum potassium and to the toxic effects of injected potassium chloride. Am. J. Physiol. 130: 747.

15. Drescher, A. N., N. B. Talbot, P. A. Meara, M. Terry, and J. D. Crawford. 1958. A study of the effects of excessive potassium intake upon body potassium stores. J. Clin. Invest. 37: 1316. 